\title{
Dual stimuli responsive poly( $N$-isopropylacrylamide) coated chitosan scaffolds for controlled release prepared from a non residue technology
}

\author{
Márcio Temtemª, Telma Barroso ${ }^{\mathrm{a}}$, Teresa Casimiro ${ }^{\mathrm{a}}$, João F. Mano ${ }^{\mathrm{b}, \mathrm{c}}$, Ana Aguiar-Ricardo ${ }^{\mathrm{a}, *}$ \\ a REQUIMTE, Departamento de Química, Faculdade de Ciências e Tecnologia, Universidade Nova de Lisboa, 2829-516 Caparica, Portugal \\ b 3Bs Research Group-Biomaterials, Biodegradables and Biomimetics, Univeristy of Minho, AvePark, Zona Industrial da Gandra, S. Cláudio do Barco, \\ 4806-909 Caldas das Taipas, Guimarães, Portugal \\ c IBB - Institute for Biotechnology and Bioengineering, PT Government Associated Laboratory, Guimarães, Portugal
}

\section{A R T I C L E I N F O}

\section{Article history:}

Received 29 July 2011

Received in revised form 15 October 2011

Accepted 26 October 2011

\section{Keywords:}

Stimuli responsive polymers

Supercritical carbon dioxide

Chitosan

PNIPAAm

Drug delivery

Ibuprofen

BSA

\begin{abstract}
A B S T R A C T
The first decade of the 21st century saw an increasing interest in the development of devices and biomaterials for delivery of bioactive substances that can be controlled by external stimuli. Herein we report the production of smart partially biodegradable scaffolds that exhibit $\mathrm{pH}$ - and temperatureresponsive behavior and their effects on the release of a model protein and a drug of low molecular weight. Chitosan (CHT) scaffolds ( $\mathrm{pH}$ sensitive) were coated/impregnated with a thermoresponsive polymer, poly( $N$-isopropylacrylamide) (PNIPAAm), by in situ synthesis of PNIPAAm within CHT micropores. Microarchitectural analysis by scanning electron microscopy and mercury intrusion porosimetry demonstrate that the coating of the pores inner structure could be efficiently achieved without a considerable loss of porosity of native CHT-scaffolds. Two different strategies were used to impregnate the polymeric devices: supercritical fluid impregnation for scaffold uptake with a model low molecular weight drug (ibuprofen) and bulk loading to impregnate a model protein (bovine serum albumin, BSA). The release profiles showed a specific pattern according to $\mathrm{pH}$ and temperature. PNIPAAm temperature responsiveness is able to control BSA release but ibuprofen (Ibu) release is only mediated by pH environmental conditions.
\end{abstract}

(c) 2011 Elsevier B.V. All rights reserved.

\section{Introduction}

Specific delivery of drugs to a target site is essential to increase their efficacy and decrease their side effects. The development of external regulated delivery systems designed to deliver drugs and/or active agents at a constant rate over a certain period of time results from the demand of better control and also from the need of prolonged drug administration [1,2]. During the last years several devices were presented as being able to control the release of drugs with different stimuli: $\mathrm{pH}$ [3-5], temperature [6-8], magnetic $[9,10]$ and electric fields [11]. Particular interest has been given to $\mathrm{pH}$ or temperature responsive materials because these two factors can be easily controlled and applicable both in vitro and in vivo conditions.

For biomedical applications it is important to circumvent, whenever possible, harmful solvents during polymer synthesis/processing and the accumulation of toxic low molecular weight compounds. In this work supercritical carbon dioxide $\left(\mathrm{scCO}_{2}\right)$ was used to prepare dual stimulus chitosan (CHT) scaffolds coated

\footnotetext{
* Corresponding author. Tel.: +351 212949 648; fax: +351212948 550 .

E-mail address: aar@dq.fct.unl.pt (A. Aguiar-Ricardo).
}

with a thermoresponsive polymer, poly( $N$-isopropylacrylamide) (PNIPAAm) leading to highly pure materials without any organic residues. PNIPAAm is a thermosensitive hydrogel that has a lower critical solution temperature (LCST), around $32{ }^{\circ} \mathrm{C}$ in aqueous solutions, close to the body temperature, so that it has a potential use for drug delivery in humans $[2,12,13]$. The LCST of this polymer is the result of a fine balance of hydrophilic and hydrophobic groups in their molecular structure [14]. At temperatures lower than $32^{\circ} \mathrm{C}$, the gel is swollen whereas at temperatures higher than $32^{\circ} \mathrm{C}$, the gel dehydrates to the collapsed state due to the breakdown of the delicate hydrophilic/hydrophobic balance in the network structure forming a separate phase $[15,16]$. Chitosan is a derivative of chitin, a natural polysaccharide, which exhibits a variety of physicochemical and biological properties, therefore it has found a series of applications in the medical field including dialysis membranes, contact lenses, antitumor uses, drug delivery controlled release devices and tissue engineering [17-21].

The combination of smart surfaces with porous structures for a controlled drug delivery device is a desired goal. Temtem et al. $[22,23]$ has demonstrated that $\mathrm{scCO}_{2}$ can be used as a carrier to homogeneously distribute the hydrogel monomer, NIPAAm within the micropores of CHT scaffolds as well as inside microporous structure of polysulfone membranes, and there it can act as solvent to 


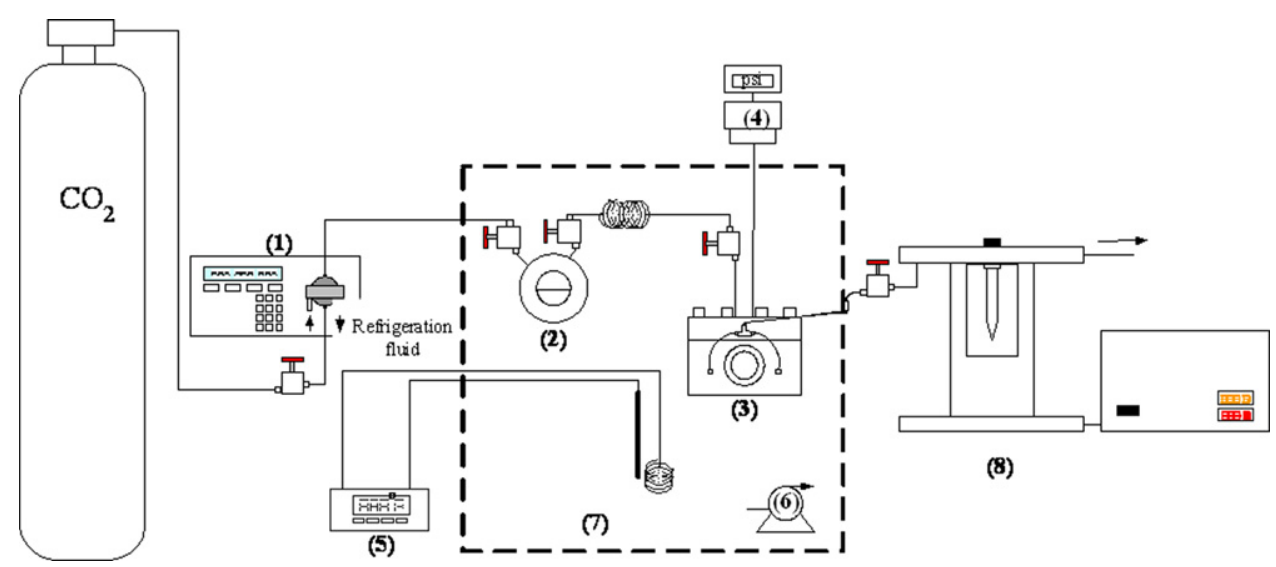

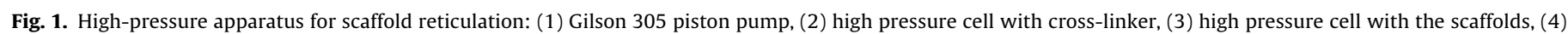
pressure transducer, (5) temperature controller, (6) recirculation pump, (7) thermostated water bath, and (8) back pressure regulator.

perform the in situ polymerizations. Herein the same methodology is extended to prepare smart devices for controlled drug release. The performance of the CHT scaffolds coated/impregnated with PNIPAAm as controlled release devices was investigated using a low molecular weight drug (ibuprofen) and a model protein, bovine serum albumin (BSA). Two different strategies were tested to incorporate the model compounds into the scaffolds: (i) supercritical fluid impregnation of a low molecular weight model drug, ibuprofen (Ibu), and (ii) scaffold bulk loading with bovine serum albumin (BSA) by adding the model protein to the polymeric solution before freeze-drying. The in vitro Ibu and BSA release profiles were analyzed together with an extensive physicochemical characterization to evaluate the effects of $\mathrm{pH}$ and temperature environment conditions on the delivery performance of these PNIPAAm-coated CHT dual stimuli responsive scaffolds.

\section{Experimental}

\subsection{Materials}

Chitosan (75-85\% deacetylated, medium molecular weight), $\mathrm{N}$-isopropylacrylamide (NIPAAm, 97\% purity), N,N-methylenebisacrylamide (MBAm, purity $\geq 85 \%$ ), 2,2'-azobis(isobutyronitrile) (AIBN, 98\% purity), bovine serum albumin (BSA, purity $\geq 98 \%$ ), glutaraldehyde (GA, $50 \mathrm{wt} . \%$ in water), ibuprofen $(99 \%$ purity) and acetic acid (purity $\geq 99 \%$ ) were purchased from Sigma-Aldrich. Carbon dioxide was obtained from Air Liquide with 99.998\% purity. All materials and solvents were used as received without any further purification.

\subsection{Cross-linked chitosan scaffolds preparation}

Scaffolds were prepared following the procedure described by Madihally and Matthew [24]. In a typical procedure 3\% (w/w total) chitosan solutions were prepared by dissolving the polymer in diluted acetic acid aqueous solution $(1 \% \mathrm{v} / \mathrm{v})$. The solution was placed in glass tubes and freezing was accomplished by immersing the tubes, containing $3 \mathrm{~mL}$ of solution, in freezing baths maintained at $-20^{\circ} \mathrm{C}$. The samples were then lyophilized (Telstar cryodos-50) until dry. The 3D structures were reticulated using a $\mathrm{CO}_{2}$ flow saturated with GA applying an apparatus schematically represented in Fig. 1. Typically, a GA solution $1 \% \mathrm{v} / \mathrm{v}$ in water is placed in an $11 \mathrm{~mL}$ high pressure vessel (2), which contains two sapphire windows on the top and on the bottom allowing the inner view of the cell and the scaffolds are located in a similar high pressure visual cell (3) with a capacity of $11 \mathrm{~mL}$ [25]. During $10 \mathrm{~min}$, a constant $\mathrm{CO}_{2}$ flow rate of $9.8 \mathrm{~g} / \mathrm{min}$ (saturated with GA) passes through the vessel containing the scaffolds inducing their cross-linking. After this procedure, a pure $\mathrm{CO}_{2}$ flow is passed through the vessel where the scaffolds are placed during $1 \mathrm{~h}$ to remove any traces of GA. The pressure in the apparatus is monitored using a pressure transducer (Setra Systems Inc., Model 204) and controlled to 20 MPa using back pressure regulator (8) (Jasco 880-81). The temperature is also maintained constant $\left(40^{\circ} \mathrm{C}\right)$, by means of a controller (5) (Hart Scientific, Model 2200), during the whole process. At the end of operation, the system is slowly depressurized during $10 \mathrm{~min}$.

\subsection{Coating of cross-linked chitosan scaffolds with PNIPAAm}

Coating with the thermoresponsive polymer was undertaken in a high pressure apparatus already described in previous works $[22,26]$. The high-pressure view cell interior is divided in two parts by a porous plate in order to avoid any direct contact between the CHT scaffolds (located in the top part of the cell) and the monomer added to the bottom of the cell. In a typical polymerization procedure, monomer, scaffolds, cross-linking agent (MBAm, 1\% w/w) and initiator (AIBN, $2 \% \mathrm{w} / \mathrm{w}$ ) are loaded into the high pressure cell which is then sealed and nitrogen is added to purge the cell and to test possible leaks. The nitrogen is slowly released and liquid carbon dioxide is loaded into the cell using a high-pressure compressor. The cell is immersed in the water bath and temperature and pressure are allowed to rise to the required experimental conditions. Additional $\mathrm{CO}_{2}$ may be added to reach the exact desired pressure. The reactions were performed at $65^{\circ} \mathrm{C}$ and $20 \mathrm{MPa}$. At these experimental conditions there is a homogeneous phase with all the reactants completely soluble in the supercritical medium. $\mathrm{CO}_{2}$ is used as a carrier of the monomer/initiator/cross-linker into the porous structure as well as a reaction medium. The reaction proceeded for $24 \mathrm{~h}$ under stirring. After this period, the reaction was stopped and the resulting PNIPAAm-coated scaffolds were washed with fresh pressurized $\mathrm{CO}_{2}\left(65^{\circ} \mathrm{C}, 20 \mathrm{MPa}\right)$, for $1 \mathrm{~h}$, in order to extract the remaining residues of unreacted monomer and crosslinking agent.

\subsection{Scaffolds characterization}

Scaffolds before and after coating were characterized using Scanning Electron Microscopy (SEM) from Hitachi S-2400, with an accelerating voltage set to $20 \mathrm{kV}$. For cross-section analysis, scaffold samples were frozen and fractured in liquid nitrogen. All samples were coated with gold before analysis. Fourier transform infrared (FT-IR) was used to study the interactions between chitosan and PNIPAAm after impregnation. FT-IR spectra of the materials were carried out using $\mathrm{KBr}$ tablets $(1 \% \mathrm{w} / \mathrm{w}$ of product in $\mathrm{KBr})$ with a 
resolution of $1 \mathrm{~cm}^{-1}$ and 16 scans per sample on a Winfirst Lite equipment.

Equilibrium hydration or swelling degree $(W, \%)$ of scaffolds impregnated/coated with PNIPAAm was determined as defined by Eq. (1):

Water content, $\quad W(\%)=\left(\frac{W_{t}-W_{d}}{W_{d}}\right) \times 100$

where $W_{d}$ is the weight of the dried polymer sample and $W_{t}$ is the weight after a certain time $(t)$. The measurements were performed with 3 replicas in order to verify the reproducibility of the experimental data. Phosphate-buffered solution ( $\mathrm{pH} 7.4)$ and acetate-buffered solution ( $\mathrm{pH} 5.5)$ with the same ionic strength were used. The oscillatory swelling experiments were conducted to investigate whether the scaffolds presented any response to the environmental $\mathrm{pH}$ and temperature changes and if these changes were reversible and to examine how fast the scaffolds could respond to the stimuli.

Mercury intrusion porosimetry (micromeritics, autopore IV) was used to study the scaffold porosity and pore size distributions before and after coating with PNIPAAm.

The in vitro biodegradability of the scaffolds was followed in $20 \mathrm{~mL} 0.1 \mathrm{M}$ PBS at $\mathrm{pH} 7.4$ and $37^{\circ} \mathrm{C}$ containing $2 \mu \mathrm{g} / \mathrm{mL}$ lysozyme. The initial weight of each sample was determined $\left(W_{i}\right)$. Every three days, samples were removed from the medium, washed with distilled water, lyophilized for $4 \mathrm{~h}$ and then weighted $\left(W_{f}\right)$. The lysozyme solution was refreshed weakly to ensure the continuous enzyme activity over the scaffolds degradation. The extent of the in vitro degradability was expressed as percentage of weight loss of the dried scaffolds ( $n=3$ after each scaffold) after lysozyme treatment. To separate between the enzymatic degradation and the dissolution of the porous structure, control samples were stored for 24 days under the same conditions as the previous ones, but without adding lysozyme [27]. Percentage weight remaining was calculated using Eq. (2):

Water content, $W(\%)=100-\left(\frac{W_{i}-W_{f}}{W_{i}}\right) \times 100$

where $W_{i}$ is the dry weight of the sample before starting the degradation experiment, $W_{f}$ is the dry weight of the sample after degradation at a certain moment of time since the starting of the degradation test. Values are expressed with the mean \pm standard deviation.

\subsection{Bulk drug loading}

BSA was loaded into the chitosan scaffolds by co-dissolving it in the solvent (acidified water) with the polymer and the scaffolds were prepared in the same mode as reported above in Section 2.2. Due to the negligible solubility of the BSA in $\mathrm{scCO}_{2}$ it was assumed that the amount of protein placed in the solution remained unmodified in the smart "scaffolds" after the reticulation and impregnation/coating procedures.

\subsection{Drug loading by supercritical fluid impregnation}

CHT scaffolds were impregnated with ibuprofen using the same high-pressure cell used for the in situ polymerizations. The impregnations assays were performed at $40^{\circ} \mathrm{C}$ and $20 \mathrm{MPa}$ using an excess of Ibu. After $24 \mathrm{~h}$ of continuous stirring the high pressure vessel was rapidly depressurized (approximately $4 \mathrm{MPa} / \mathrm{min}$ ).

\subsection{Controlled release studies}

Small portions of the scaffold (around $20 \mathrm{mg}$ ) were placed inside $100 \mathrm{~mL}$ buffer solutions at different $\mathrm{pH}$ (7.4 or 5.5) and temperatures ( 37 and $20^{\circ} \mathrm{C}$ ). $1 \mathrm{~mL}$ aliquots were withdrawn periodically from the solutions and collected. $1 \mathrm{~mL}$ of fresh medium was added in each process. Quantification of the released drug takes into account the portion of solution that was removed from the released solution. Ibuprofen was quantified by UV spectroscopy (Helios Alpha Double-Beam UV/VIS Spectrophotometer) using maximum absorbance around $220 \mathrm{~nm}$ and BSA at $280 \mathrm{~nm}$.

\section{Results and discussion}

\subsection{Scaffold preparation and morphological characterization}

In this study, an environmentally friendly methodology is applied to produce thermoresponsive devices using supercritical fluid technology. The incorporation of a fraction of a thermoresponsive polymer can provide other properties to the scaffolds including improved or switchable release control of impregnated bioactive agents, such as growth factors, or control of the cell adhesion/detachment. $\mathrm{ScCO}_{2}$ was used as a carrier to homogeneously distribute the monomer, initiator and cross-linker within the pores of the scaffold which act as micro-reactors. Fig. 2 presents SEM images of the materials prepared in this work before and after the coating procedure (Fig. $2 \mathrm{a}$ vs b). Fig. $2 \mathrm{c}$ and d shows the magnified views of the coated pores highlighting the different coverings. Micrographs show that a visible hydrogel layer is uniformly distributed along the walls of the pores. A very small number of pores were completely full with the hydrogel (Fig. 2c).

The FT-IR spectra of CHT, PNIPAAm and PNIPAAm-coated CHT scaffolds are depicted in Fig. 3 for the region $1200-2200 \mathrm{~cm}^{-1}$. The absorption band of PNIPAAm at $1643 \mathrm{~cm}^{-1}$ and $1539 \mathrm{~cm}^{-1}$ are assigned to amide I and amide II vibrations, respectively [28]. The main contribution to amide I band is the carbonyl stretching mode, whereas the amide II is mainly due to the in-plane $\mathrm{N}-\mathrm{H}$ bending. In the FT-IR spectrum of PNIPAAm-coated CHT scaffolds the amide I band shifts to lower wavenumbers indicating that the carbonyl group of PNIPAAm was additionally engaged in $\mathrm{H}$-bonding with the free primary amino group $\left(-\mathrm{NH}_{2}\right)$ of CHT. Additionally, there is also a small shift of the amide II band to higher wavenumbers for the PNIPAAm-coated CHT scaffolds comparing to pure PNIPAAm, as it was expected due to the high desacetylation degree of CHT.

Mercury intrusion porosimetry (Fig. 4) was used to characterize surface area and porosity. Before coating, the raw scaffolds presented a median pore diameter of $17.9 \mu \mathrm{m}$ while after reaction this value decreased to $16.3 \mu \mathrm{m}$. No major differences were observed for porosity data; raw and coated scaffolds show an average porosity of $85 \%$ confirming that the coating procedure was efficient enough to cover the outer and inner surface of the scaffolds without blocking the pores or dramatically changing the pores interconnectivity.

The swelling degree of the dual stimulus scaffolds is also an important property to be characterized because it will determine properties such as the adsorption and diffusion of solutes through the hydrogel, the mechanical properties under wet conditions and the water uptake ability. Fig. 5a shows the swelling behavior, at $20^{\circ} \mathrm{C}$ and $37^{\circ} \mathrm{C}$, for the smart devices produced in $\mathrm{scCO}_{2}$. As it was expected the swelling increased with a decrease in the temperature [22]. It is well known that the hydrophilic/hydrophobic balance of the PNIPAAm hydrogels is due to the existence of the amide hydrophilic groups and the isopropyl hydrophobic groups in the side chains [29]. When the temperature is above the LCST hydrophobic interactions among isopropyl groups increase and hydrogen bonding between the amide group and surrounding water molecules are weak. When the temperature decreases, the hydrogen bonding between the hydrophilic segments of the polymer chain and water molecules are dominant, leading to a swelling increase. This suggests that it should be possible to control the 

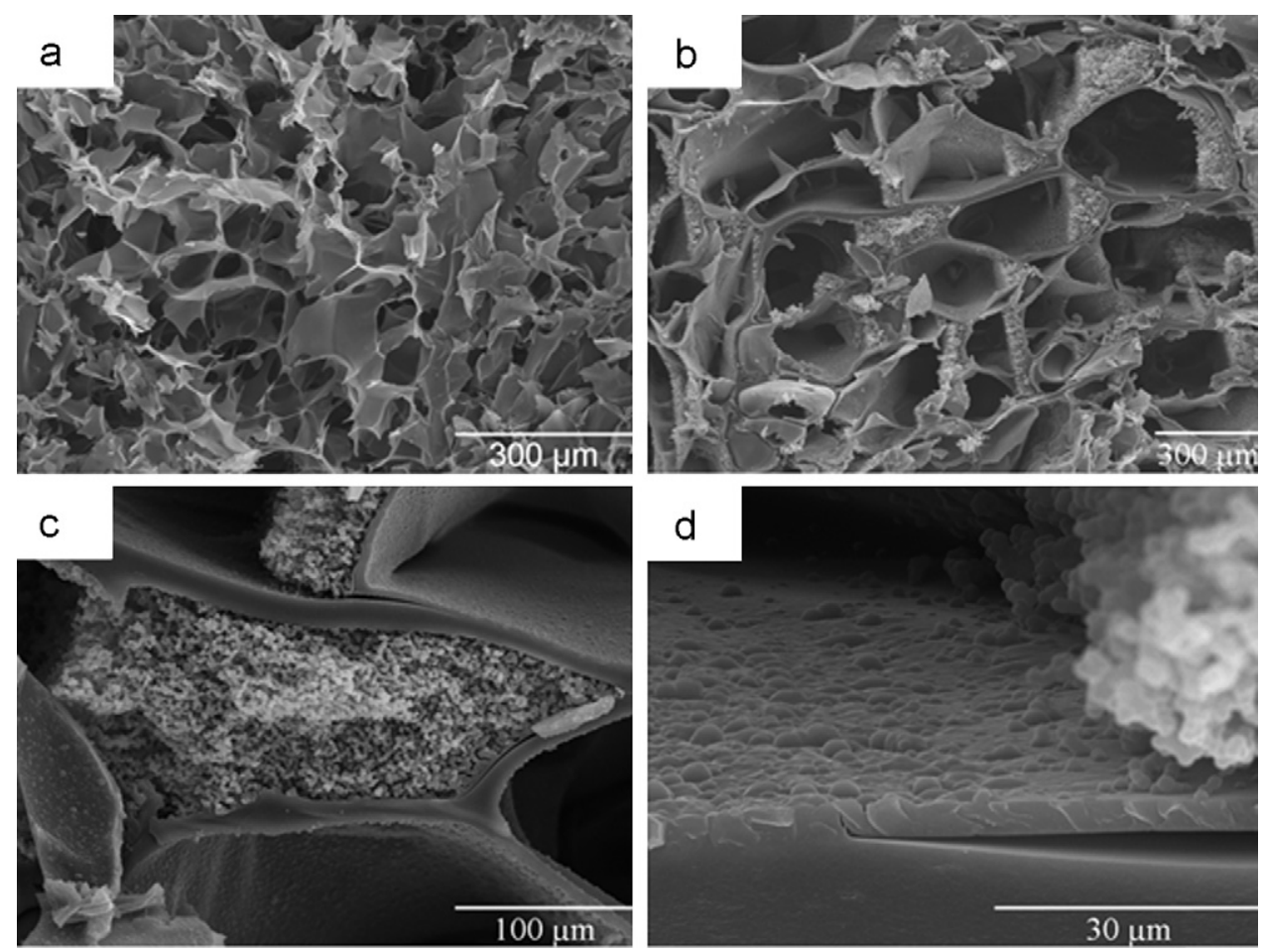

Fig. 2. Scanning electron micrographs of CHT scaffolds (a) native and (b) PNIPAAm-coated; (c) and (d) images are magnified views of coated pores highlighting the different coverings.

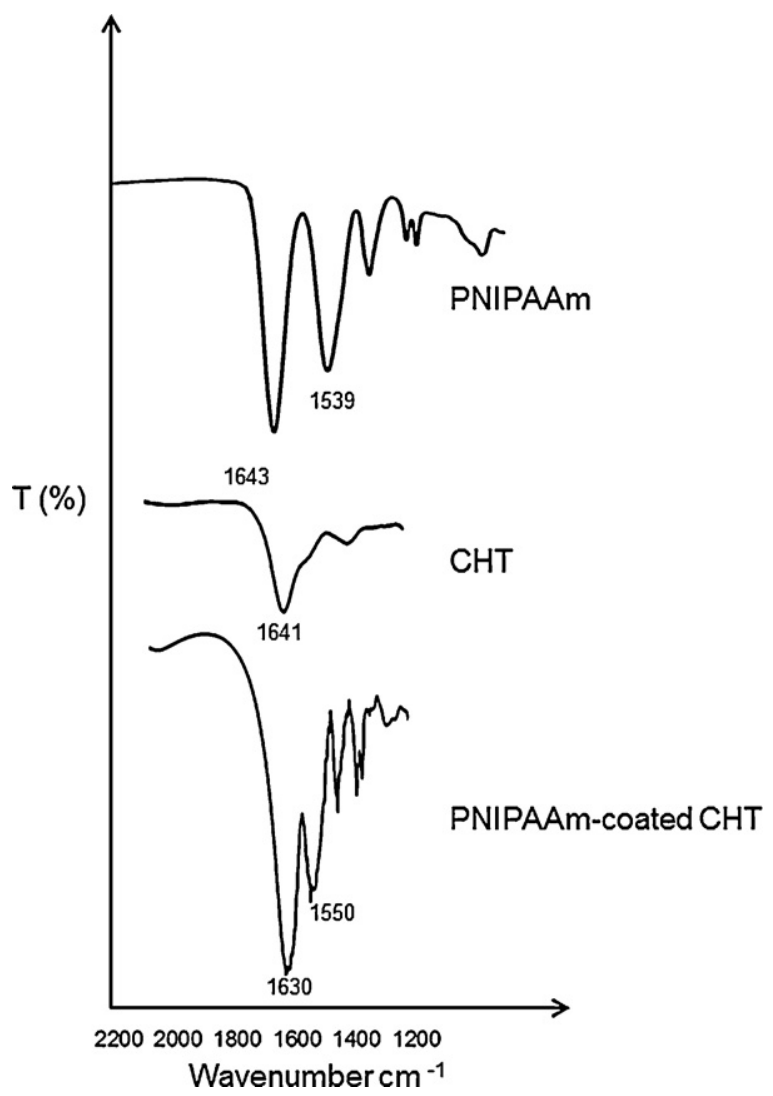

Fig. 3. FT-IR spectra recorded at room temperature in the $1200-2200 \mathrm{~cm}^{-1}$ region for PNIPAAm microparticles, CHT scaffold and PNIPAAm-coated CHT scaffold. release of molecules by simply adjusting the temperature. No temperature responsiveness was observed for CHT scaffolds that were not coated.

It would also be a desirable characteristic to have $\mathrm{pH}$-sensitive controlled-release scaffolds with controllable swelling ability. The results plotted in Fig. 5b demonstrate that the native and PNIPAAmcoated scaffolds change their ability to absorb solution when the environmental $\mathrm{pH}$ is altered. The Donnan theory states that the swelling ability is basically determined by the osmotic pressure gradient between the inside and outside of a gel [30]. Therefore, from a macroscopic point of view, the swelling phenomenon appears to be a balance of the osmotic pressure gradient or concentration gradient between the interior of the hydrogel and the external solution. At higher $\mathrm{pH}$, the degree of ionization is reduced, due to the

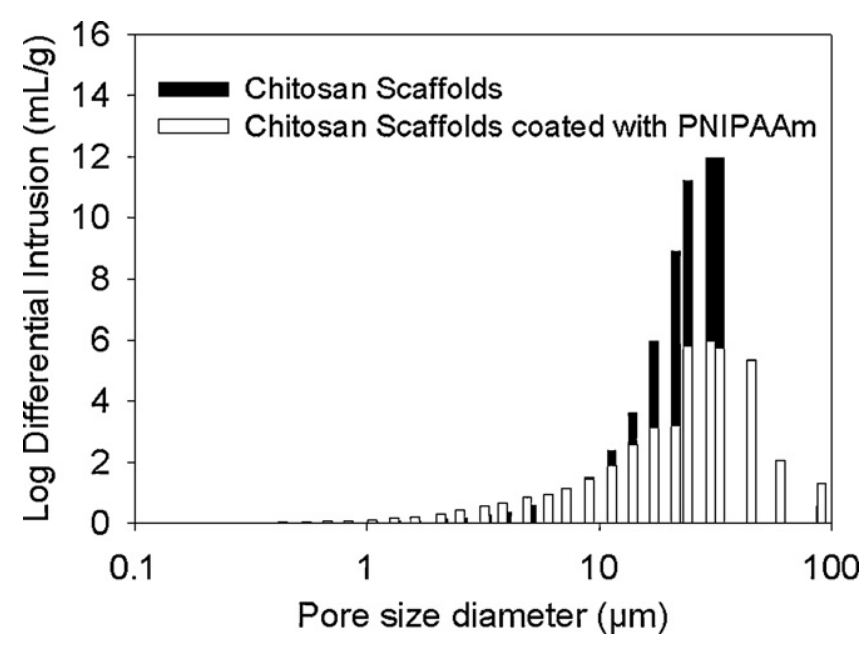

Fig. 4. Pore size distribution of bulk CHT scaffolds and PNIPAAm-coated CHT scaffolds as obtained by mercury intrusion porosimetry. 

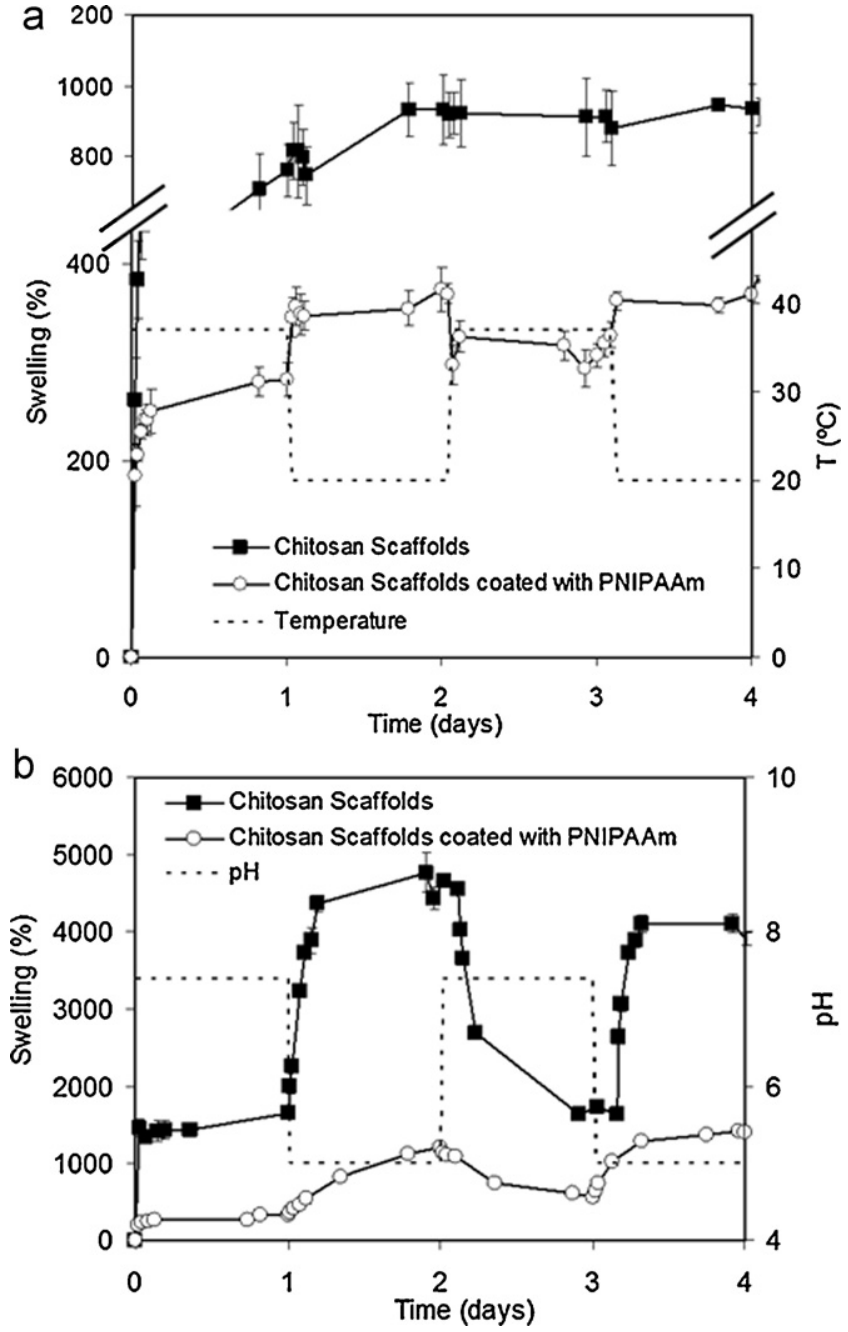

Fig. 5. Equilibrium volume swelling ratio of CHT scaffolds and PNIPAAm-coated scaffolds with (a) temperature pulses between 20 and $37^{\circ} \mathrm{C}$ in $\mathrm{PBS}$ (pH 7.4), (b) pH pulses between 5.5 and 7.4 in a buffered solution at $37^{\circ} \mathrm{C}$. All samples were tested in triplicate. Where not shown, errors bars are smaller than the data symbols.

deprotonation of CHT amino units [31,32] decreasing the swelling of samples as the osmotic pressure and charge repulsion decrease. As it was expected this behavior is higher in the scaffolds that were not coated.

Scaffolds were immersed for 24 days in phosphate buffer solution (PBS) and in PBS solution containing lysozyme to investigate their biodegradability, as lysozyme is the main enzyme responsible for CHT degradation in the body [33]. After 25 days of the scaffolds immersion in PBS less than $5 \%$ of mass loss was observed. In the experiments using lysozyme solutions a mass loss of $5 \%$ was observed after 5 days of scaffolds immersion, as can be seen from the results of the biodegradability assays summarized in Fig. 6. The results show that the mass loss is due to the chitosan degradability accelerated in the presence of lysozyme (Fig. 6b). As expected, a higher mass loss is observed for coated scaffolds as any CHT portions degraded comprise the PNIPAAm layer that is coating the CHT surface. NMR analysis (data not shown) showed that no NIPAAm or GA residues could be detected from aqueous solutions where scaffolds were immersed during the time length of biodegradability tests, the conclusion was that the weight loss could not be due to the release of any monomer or cross-linking agent.
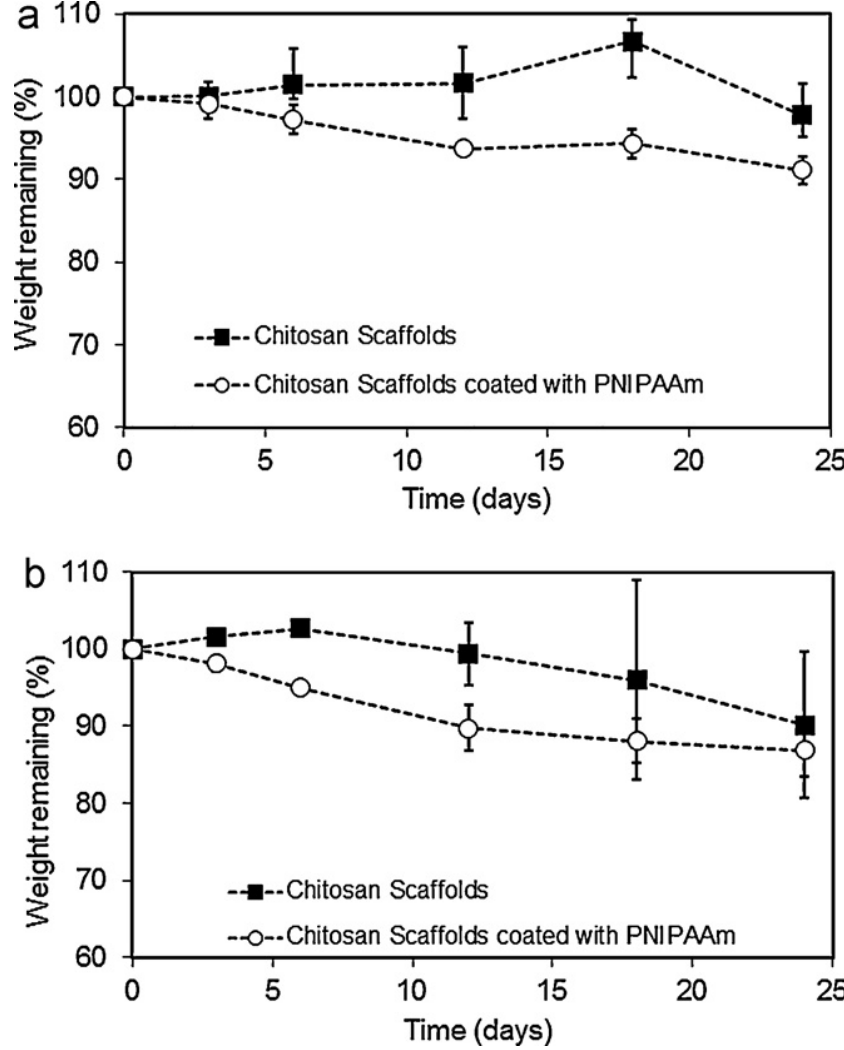

Fig. 6. Biodegradability of the PNIPAAm-coated CHT scaffolds in ( $\mathbf{\square})$ PBS and $(O)$ PBS with lysozyme.

\subsection{Drug/protein release studies}

From the point of view of the potential utility of PNIPAAm/chitosan matrixes as controlled delivery systems, it is crucial to know the release kinetics under different physiological conditions and to analyze if they are capable to encapsulate molecules and release them when triggered by a small change in temperature or $\mathrm{pH}$. The potential of the obtained structures as controlled releases devices was evaluated using a model drug, ibuprofen, and a model protein, bovine serum albumin (BSA). Supercritical mixing and impregnation is simple and highly more attractive as it avoids the use of organic solvents [34]. According to the report of Kazarian and Martirosyan [35], there are two mechanisms of supercritical fluid impregnation of drugs into polymer matrixes, i.e., simple deposition and preferential partitioning. In this work, Ibu was efficiently impregnated into the CHT porous matrix due to the high solubility of the drug in the supercritical fluid [36] and preferential deposition on the hydrogel structure although the high glass transition temperature $\left(T_{g}\right)$ of $\mathrm{CHT}\left(203^{\circ} \mathrm{C}\right)$ [37]. In the tested conditions, approximately $160 \mathrm{mg}$ of drug were loaded per gram of scaffold. BSA was incorporated into the scaffolds by bulk loading prior to the liophilization step with $1 \mathrm{~g}$ of protein per gram of scaffold. As we already described, BSA loaded scaffolds were then coated with PNIPAAm.

Drug dissolution tests were conducted to investigate the drug release behaviors from the CHT-Ibu impregnated-scaffolds and from CHT-BSA loaded scaffolds. Fig. 7 draws the overall release curves at different $\mathrm{pH}\left(5.5\right.$ and 7.4) and temperature $\left(20^{\circ} \mathrm{C}\right.$ and $37^{\circ} \mathrm{C}$ ) conditions. The immediate Ibu and BSA release which occurs in the first few minutes is mainly governed by dissolution of the unloaded bioactive molecules that are only adsorbed or dispersed on the chitosan matrix surface. After the initial burst release stage, the swelling effect, resulting from different stimuli, $\mathrm{pH}$ or $T$, become 

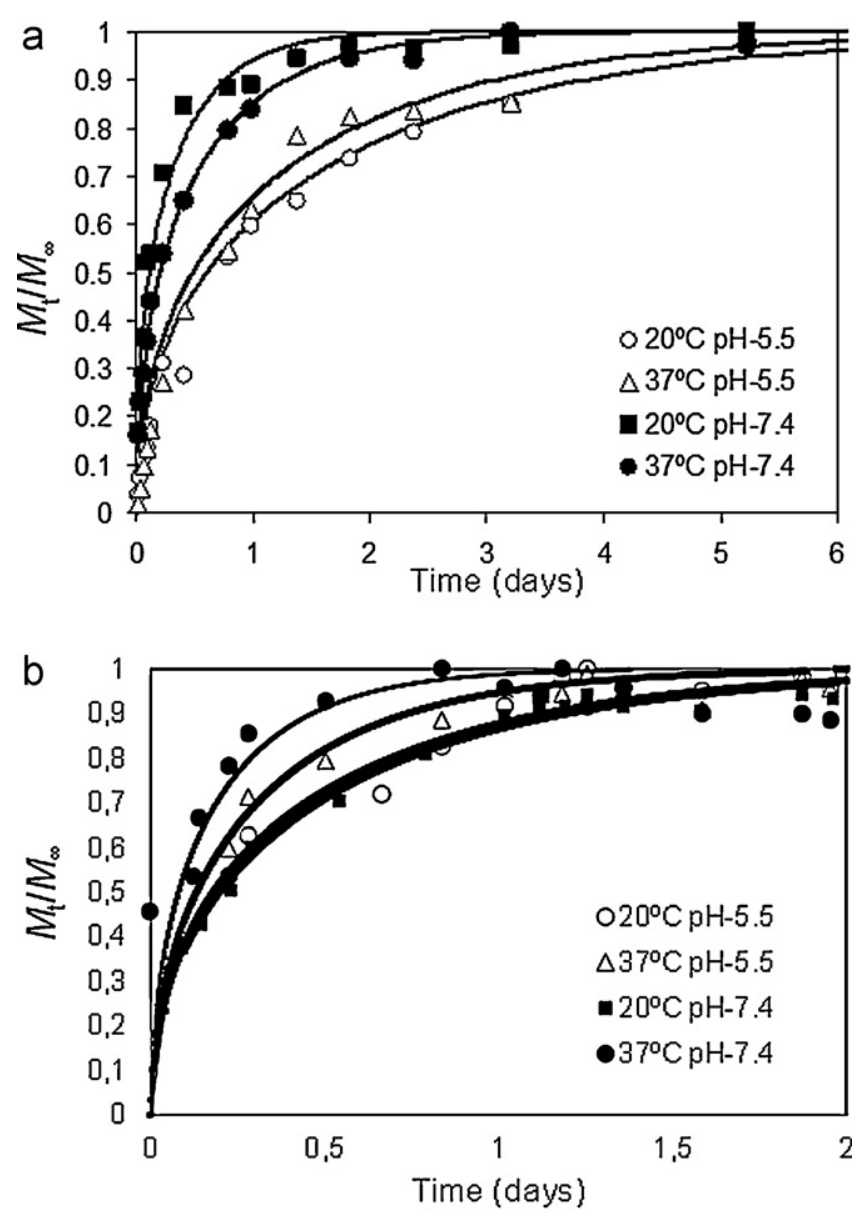

C
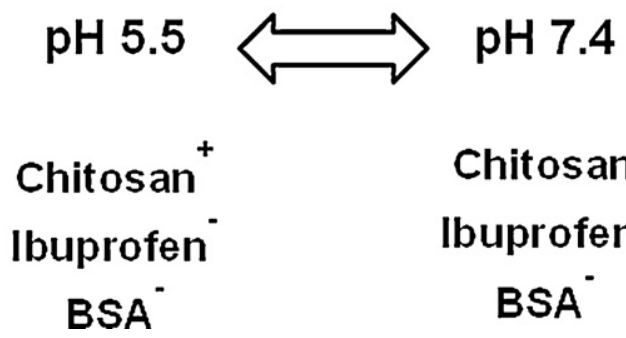

\section{Chitosan Ibuprofen BSA}

Fig. 7. Release of bioactive molecules from PNIPAAm-coated scaffolds at different $\mathrm{pH}$ and $T$ conditions. Marks stand for experimental data and full lines stand for fitted curves according to Fick's second law in cylindrical systems. (a) Ibuprofen release; (b) BSA release and (c) scheme showing the electrostatic charges of CHT, Ibu and BSA present as a function of $\mathrm{pH}$ conditions.

more important. Fig. 7a shows that after 6 days most of the Ibu was released from the scaffold. To evaluate the influence of the different stimuli in the diffusion of ibuprofen and BSA a simple model was developed. Fick's second law in cylindrical systems, considering axial and radial mass transfer, may be used to describe the drug transport $[38,39]$ according to Eq. (3):

$$
\begin{aligned}
\frac{M_{t}}{M_{\infty}}= & 1-\frac{32}{\pi^{2}} \sum_{n=1}^{\infty} \frac{1}{q_{n}^{2}} \exp \left(-\frac{q_{n}^{2}}{R^{2}} D t\right) \\
& \times \sum_{p=0}^{\infty} \frac{1}{(2 p+1)^{2}} \exp \left(-\frac{(2 p+1)^{2} \pi^{2}}{H^{2}} D t\right)
\end{aligned}
$$

where $M_{t}$ and $M_{\infty}$ denote the absolute cumulative amounts of drug released at time $t$ and infinity, respectively; $n$ and $p$ denote dummy variables; the $q_{n}$ are the roots of the Bessel function of the first kind
Table 1

Diffusion coefficients of ibuprofen and BSA release.

\begin{tabular}{llr}
\hline & \multicolumn{1}{c}{$\mathrm{D} /\left(10^{-12} \mathrm{~m}^{2} / \mathrm{s}\right)$} & \\
\cline { 2 - 3 } & Ibuprofen & BSA \\
\hline $20^{\circ} \mathrm{C} ; \mathrm{pH} \mathrm{7.4}$ & 20 & 27 \\
$37^{\circ} \mathrm{C} ; \mathrm{pH} 7.4$ & 12 & 70 \\
$20^{\circ} \mathrm{C} ; \mathrm{pH} 5.5$ & 4 & 10 \\
$37^{\circ} \mathrm{C} ; \mathrm{pH} 5.5$ & 5 & 35 \\
\hline
\end{tabular}

of zero order $\left[J_{0}\left(q_{n}\right)=0\right]$, and $R$ and $H$ denote the radius and height of the cylinder that represents the scaffold shape, and were 2.5 and $5 \mathrm{~mm}$, respectively.

Table 1 lists the diffusion coefficients $(D)$ that were used to adjust the mathematical model to experimental Ibu and BSA release curves in the different environments. A good fitting was achieved suggesting a Fick's behavior for the release of the model drugs. Comparing these results with ibuprofen and BSA release profiles at each temperature, it is possible to observe that both bioactive molecules are released more slowly at $\mathrm{pH}$ 5.5. If $\mathrm{CHT}$ swelling was paramount higher diffusion coefficients should be obtained at lower $\mathrm{pH}$. However, at pH 5.5 the scaffold surface and the bioactive molecules are oppositely charged and thus strong attractive electrostatic forces between CHT-Ibu and CHT-BSA are present (Fig. 7c). Under acidic conditions, at $\mathrm{pH}$ below the $\mathrm{p} K_{\mathrm{a}}$ of chitosan (6.5), the CHT amino groups are almost completely protonated, and thus the chitosan charge density is positive in opposition to ibuprofen and BSA that are negatively charged. Ibuprofen has carboxylic acid groups with a $\mathrm{p} K_{\mathrm{a}}$ of 4.4 and BSA's isoelectric point is usually reported as 4.8-5.2 [40] therefore at both pHs either Ibu molecules or BSA are deprotonated. The strong attractive electrostatic forces between CHT-Ibu and CHT-BSA prevail and withdraw the effect of swelling. Moreover, at $20^{\circ} \mathrm{C}$ and $\mathrm{pH} 5.5$ the coated CHT-scaffolds present the maximum swelling and the PNIPAAm chains are in the hydrophilic state interacting through hydrogen bonding with water. In this case, the surface of unit cells become less crowded and PNIPAAm chains extend outside the unit cell creating a network which can cause a delay in protein release due to the interactions between BSA and PNIPAAm extended chains. When "smart" CHT-scaffolds are placed at $37^{\circ} \mathrm{C}$ the released amount of BSA increases. At this temperature, the hydrogen bonding with water molecules are disrupted and the PNIPAAm chains consequently collapse and displace the water molecules, thus, the possible interactions between protein and polymer chains are avoided enabling an easier BSA release. At $\mathrm{pH} 7.4$, CHT is no longer protonated, the results obtained for 20 and $37^{\circ} \mathrm{C}$ are contrary, while Ibu has a higher diffusion coefficient at the lowest temperature, BSA diffuses faster at $37^{\circ} \mathrm{C}$. Comparing the overall data it is possible to attain the following order for the BSA release: $\left(37^{\circ} \mathrm{C}, \mathrm{pH} 7.4\right)>\left(37^{\circ} \mathrm{C}, \mathrm{pH} 5.5\right)>\left(20^{\circ} \mathrm{C}, \mathrm{pH} 7.4\right)>\left(20^{\circ} \mathrm{C}\right.$, $\mathrm{pH}$ 5.5). Matching the diffusion coefficients of Ibu and BSA at different $\mathrm{pH}$ and $T$ release conditions, the conclusion is that Ibu presents lower diffusion coefficients than BSA at whatever conditions and this is due to its low molecular weight. Small molecules are able to go all over the available space in the matrix and can cross the smaller interstices of the scaffold matrix, so they have longer diffusion pathways. High molecular weight molecules can only diffuse across larger pores and consequently higher diffusion coefficients are achieved. It is interesting to notice that at $37^{\circ} \mathrm{C}$ and $\mathrm{pH} 7.4$ the BSA release is mediated by PNIPAAm barrier, while at pH 5.5 both the attractive electrostatic forces as well as PNIPAAm barrier influence the release kinetics.

\section{Conclusions}

In summary, a simple and green microscale technology is applied to produce smart porous 3D chitosan-matrixes with 
possible applications for tissue engineering applications or switchable release devices of bioactive molecules. The coating of the 3D porous structures was efficiently achieved without compromising the porosity and the biodegradability of the materials. The results demonstrate that it is possible to control the swelling by external stimulus such as $\mathrm{pH}$ and/or temperature changes and this can be used to mediate the release of bioactive molecules from highly porous materials. Moreover, the experiments showed that for the controlled release of biomolecules, the diffusion behavior is also influenced by protein-PNIPAAm interactions. PNIPAAm temperature responsiveness is able to control BSA release but ibuprofen (Ibu) release is only regulated by $\mathrm{pH}$ environmental conditions.

\section{Acknowledgments}

The authors would like to thank the financial support from Fundação para a Ciência e Tecnologia (FCT) through contracts MIT-Pt/Bs-CTRM/0051//2008, SFRH/BD/16908/2004 and SFRH/BD/62475/2009, Fundação Calouste Gulbenkian, FEDER and FSE. We wish to thank the Analytical Services Laboratory of REQUIMTE.

\section{References}

[1] C.S. Brazel, N.A. Peppas, Pulsatile local delivery of thrombolytic and antithrombotic agents using poly(N-isopropylacrylamide-co-methacrylic acid) hydrogels, J. Controlled Release 39 (1996) 57-64.

[2] J. Kost, R. Langer, Responsive polymeric delivery systems, Advanced Drug Delivery Reviews 46 (2001) 125-148.

[3] P. Gupta, K. Vermani, S. Garg, Hydrogels: from controlled release to pHresponsive drug delivery, Drug Discovery Today 7 (2002) 569-579.

[4] Y. Bae, N. Nishiyama, S. Fukushima, H. Koyama, M. Yasuhiro, K. Kataoka, Preparation and biological characterization of polymeric micelle drug carriers with intracellular $\mathrm{pH}$-triggered drug release property: tumor permeability, controlled subcellular drug distribution and enhanced in vivo antitumor efficacy, Bioconjugate Chemistry 16 (2005) 122-130.

[5] F. Li, H. Wu, H. Zhang, C.H. Gu, Q. Yang, Antitumor drug paclitaxel-loaded pH-sensitive nanoparticles targeting tumor extracellular $\mathrm{pH}$, Carbohydrate Polymers 77 (2009) 773-778.

[6] M.Nakayama, T.Okano, T. Miyazaki, F. Kohori, K. Sakai, M. Yokoyama, Molecular design of biodegradable polymeric micelles for temperature-responsive drug release, J. Controlled Release 115 (2006) 46-56.

[7] Y. Shin, J. Liu, J.H. Chang, G. Exarhos, Sustained drug release on temperatureresponsive poly( $\mathrm{N}$-isopropylacrylamide)-integrated hydroxyapatite, Chemical Communications 16 (2002) 1718-1719.

[8] N. Sanoj Rejinold, P.R. Sreerekha, K.P. Chennazhi, S.V. Nair, R. Jayakumar, Biocompatible, biodegradable and thermo-sensitive chitosa-g-poly ( $\mathrm{N}$-isopropylacrylamide) nanocarrier for curcumin drug delivery, International J. Biological Macromolecules 49 (2011) 161-172.

[9] H. Shang-Hsiu, L. Ting-Yu, H. Hsin-Yang, L. Dean-Mo, C. San-Yuan, Magneticsensitive silica nanospheres for controlled drug release, Langmuir 24 (2008) 239-244.

[10] T.Y. Liu, S.H. Hu, T.Y. Liu, D.M. Liu, S.Y. Chen, Magnetic-sensitive behavior of intelligent ferrogels for controlled release of drug, Langmuir 22 (2006) 5974

[11] I.C. Kwon, A.E. Bae, T. Okano, S.W. Kim, Drug release from electric current sensitive polymers, J. Controlled Release 17 (1991) 149-153.

[12] J.H. Cho, K. Su-Hyang, K.D. Park, M.C. Jung, W.I. Yang, S.W. Han, J.Y. Noh, J.W. Lee, Chondrogenic differentiation of human mesenchymal stem cells using a thermosensitive poly( $\mathrm{N}$-isopropylacrylamide) and water-soluble chitosan copolymer, Biomaterials 25 (2004) 5743-5751.

[13] B.L. Guo, J.F. Yuan, L. Yao, Q.Y. Gao, Preparation and release profiles of $\mathrm{pH} /$ temperature-responsive carboxymethyl, chitosan/P(2-(dimethylamino) ethyl methacrylate) semi-IPN amphoteric hydrogel, Colloid and Polymer Science 285 (2007) 665-671.

[14] E. Costa, J. de-Carvalho, T. Casimiro, C. Lobato da Silva, M.T. Cidade, A Aguiar-Ricardo, Tailoring thermoresponsive microbeads in supercritical carbon dioxide for biomedical applications, J. Supercritical Fluids 56 (2011) 292-298.
[15] J. Zhang, N. Peppas, Synthesis and characterization of $\mathrm{pH}-$ and temperaturesensitive poly(methacrylic acid)/poly(N-isopropylacrylamide) interpenetrating polymeric networks, Macromolecules 33 (2000) 102-107.

[16] H.K. Ju, S.Y. Kim, S.J. Kim, Y.M. Lee, pH/temperature-responsive semi-IPN hydrogels composed of alginate and poly(N-isopropylacrylamide), J. Applied Polymer Science 83 (2002) 1128-1139.

[17] M. Prabaharan, J.F. Mano, Chitosan-based particles as controlled drug delivery systems, Drug Delivery 12 (2005) 41-57.

[18] J.H. Cho, S.H. Kim, K.D. Park, M.C. Jung, W.I. Yang, S.W. Han, J.Y. Noh, J.W Lee, Chondrogenic differentiation of human mesenchymal stem cells using a thermosensitive poly(N-isopropylacrylamide) and water-soluble chitosan copolymer, Biomaterials 25 (2004) 5743-5751.

[19] K. Gong, J.A. Darr, I.U. Rehman, Supercritical fluid assisted impregnation of indomethacin into chitosan thermosets for controlled release applications, International J. Pharmaceutics 315 (2006) 93-98.

[20] M. Wang, Y. Fang, D. Hu, Preparation and properties of chitosan-poly(Nisopropylacrylamide) full-IPN hydrogels, Reactive and Functional Polymers 48 (2001) 215-221.

[21] N. Bhattarai, J. Gunn, M. Zhang, Chitosan-based hydrogels for controlled, localized drug delivery, Advanced Drug Delivery Review 62 (2010) 83-99.

[22] M. Temtem, T. Casimiro, J.F. Mano, A. Aguiar-Ricardo, Green synthesis of a temperature sensitive hydrogel, development and characterization of thermoresponsive polysulfone membrane using an environmental friendly technology, Green Chemistry 9 (2007) 75-79.

[23] M. Temtem, D. Pompeu, T. Barroso, J. Fernandes, P.C. Simões, T. Casimiro, A.M. Botelho do Rego, A. Aguiar-Ricardo, Development and characterization of a thermoresponsive polysulfone membrane using an environmental friendly technology, Green Chemistry 11 (2009) 638-645.

[24] V. Sundararajan, H. Madihally, W.T. Matthew, Porous chitosan scaffolds for tissue engineering, Biomaterials 20 (1999) 1133-1142.

[25] V.G. Correia, V.D.B. Bonifácio, V.P. Raje, T. Casimiro, G. Moutinho, C.L. Silva, M.G. Pinho, A. Aguiar-Ricardo, Oxazoline-based antimicrobial oligomers: Synthesis by CROP using supercritical $\mathrm{CO}_{2}$, Macromolecular Bioscience 11 (2011) 1128-1137.

[26] T. Casimiro, A.M. Banet-Osuna, A.M. Ramos, M. Nunes da Ponte, A Aguiar-Ricardo, Synthesis of highly cross-linked poly(diethylene glycol dimethacrylate) microparticles in supercritical carbon dioxide, European Polymer J. 41 (2005) 1947-1953.

[27] R. Freier, H.S. Koh, K. Kazanian, M.S. Shoichet, Controlling cell adhesion and degradation of chitosan films by N-acetylation, Biomaterials 26 (2005) 5872-5878.

28] E. Costa, M. Coelho, L.M. Ilharco, A. Aguiar-Ricardo, P.T. Hammond, Tannic acid mediated supression of PNIPAAm microgels thermoresponsive behavior Macromolecules 44 (2011) 612-621.

[29] S.X. Cheng, J.T. Zhang, R.X. Zhuo, Macroporous poly(N-isopropylacrylamide) hydrogels with fast response rates and improved protein release properties, J. Biomedical Materials Research Part A 67A (2003) 96-103.

[30] S. Gunasekaran, T. Wang, C. Chai, Swelling of pH-sensitive chitosan-poly(vinyl alcohol) hydrogels, J. Applied Polymer Science 102 (2006) 4665-4671.

[31] X. Qu, A. Wirsén, A.C. Albertsson, Synthesis and characterization of $\mathrm{pH}$-sensitive hydrogels based on chitosan and D,L-lactic acid, J. Applied Polymer Science 74 (1999) 3193-3202.

[32] X. Qu, A. Wirsén, A.C. Albertsson, Novel pH-sensitive chitosan hydrogels: swelling behavior and states of water, Polymer 41 (2000) 4589-4598.

[33] K. Tomihata, Y. Ikada, In vitro and in vivo degradation of films of chitin and its deacetylated derivatives, Biomaterials 18 (1997) 567-575.

[34] S.D. Yeo, E. Kiran, Formation of polymer particles with supercritical fluids: a review, J. Supercritical Fluids 34 (2005) 287-308.

[35] S.G. Kazarian, G.G. Martirosyan, Spectroscopy of polymer/drug formulations processed with supercritical fluids: in situ ATR-IR and Raman study of impregnation of ibuprofen into PVP, International J. Pharmaceutics 232 (2002) 81-90.

[36] M. Muntó, N. Ventosa, S. Sala, J. Veciana, Solubility behaviors of ibuprofen and naproxen drugs in liquid " $\mathrm{CO}_{2}$-organic solvent" mixtures, The J. Supercritical Fluids 47 (2008) 147-153.

[37] K. Sakurai, T. Maegawa, T. Takahashi, Glass transition temperature of chitosan and miscibility of chitosan/poly(N-vinyl pyrrolidone) blends, Polymer 41 (2000) 7051-7056

[38] J.M. Vergnaud, Controlled Drug Release of Oral Dosage Forms, Ellis Horwood, New York, 1993.

[39] J. Siepmann, F. Siepmann, Mathematical modeling of drug delivery, International J. Pharmaceutics 364 (2008) 328-343.

[40] V.A. Braz, K.J. Howard, Separation of protein oligomers by blue native gel electrophoresis, Analytical Biochemistry 388 (2009) 170-172. 